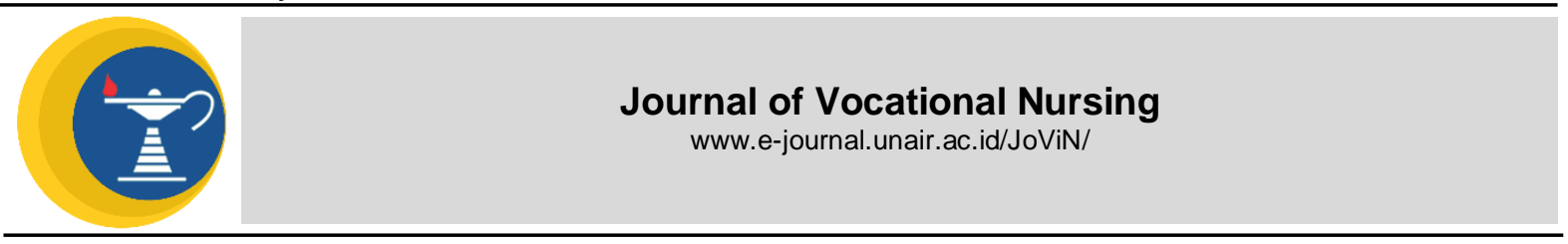

\title{
THE EFFECT OF VIRTUAL REALITY ON COGNITIVE FUNCTIONS IN LADIES WITH DEMENTIA: LITERATURE REVIEW
}

Emeltriana Emilinda Aek Seran, Joni Haryanto, and Elida Ulfiana

Faculty of Nursing, Universitas Airlangga

\section{A B S TRACT}

Introduction: The decline in cognitive function that occurs in the elderly with dementia will have an impact on decreasing daily physical and social activities in the elderly resulting in decreased quality of life for the elderly. One of the interventions that can be used to maintain cognitive function in the elderly is by using virtual reality. Purpose: The purpose of this study is to explain the effect of virtual reality on cognitive function in elderly people with dementia based on empirical studies in the last five years. Method: the process of searching for journals or articles using a database indexed by Scopus, ProQuest, and Science Direct using adequate keywords. The framework used for the review was PICOS and the inclusion criteria used were Englishlanguage journals with issues from 2015 to 2020. Data analysis and tabulation were carried out in articles or journals. Title, abstract, full text, and methodology are assessed to determine the eligibility of the article or journal. Results: 758's articles were identified, ten articles fit the research criteria. Virtual reality affects cognitive function where it can improve memory, attention, executive function and can increase the overall scale of the MoCA. The advantage over the use of virtual reality for the elderly with dementia is that it not only improves cognitive but also improves motor coordination, reduces behavioral and psychological symptoms, and can be used to detect cognitive impairments early. Conclusion: In carrying out cognitive rehabilitation programs in the elderly can use technology-based interventions by using virtual reality.
Research Report

ARTICLE INFO

Received May 21, 2021

Accepted May 28, 2021

Online May 31, 2021

${ }^{*}$ Correspondence:

Emeltriana Emilinda Aek Seran

*Email:

emeltriana.emilinda.aek-

2019@fkp.unair.ac.id

Keywords:

Dementia, Elder, Virtual Reality

\section{INTRODUCTION}

The elderly population has increased from year to year and has now become a global public health concern around the world (Nankinga et al., 2020). Increasing age and increasing prevalence of degenerative diseases are the main factors causing cognitive decline which results in an increase in the incidence of dementia in the elderly group. Dementia is a syndrome characterized by cognitive decline which includes memory, language, orientation, attention, and judgment, and shows symptoms such as depression, apathy, irritability, and obstacles in carrying out (Coeslho et al., 2020).

Dementia consists of several types, one of which is Alzheimer's. Alzheimer's is the most common type of dementia occurs in the elderly, where it accounts for about 60 to $70 \%$ of cases of dementia in the elderly (Nankinga et al., 2020). Dementia has a big impact on the life of an elderly person (Kerpershoek et al., 2018). This is one of the main causes of disability that occurs in the elderly (Lau et al., 2019). The decline in cognitive function that occurs in the elderly with dementia will have an impact on decreasing daily physical and social activities in the elderly which is a problem in public health and results in a decrease in the quality of life of the elderly (Wibowo et al., 2015).

The problem of cognitive decline in the elderly with dementia can be treated with various non-pharmacological interventions. One technology-based non-pharmacological intervention that can be used to maintain cognitive function in the elderly is by using virtual reality (Sobral and Pestana, 2020). Virtual reality is a technology that combines to increase memory's ability to explore interactions with different environments from the virtual environment. Virtual Reality combines traditional treatments that require 
repetitive actions to improve cognitive and motor skills with virtual reality computer-based simulations that are more effective and safer and are an interactive approach in the management of individuals with disabilities. (Sobral and Pestana, 2020). Therefore, the effect of the use of virtual reality on cognitive function in the elderly needs to be studied further.

The prevalence of people with dementia around the world has increased from year to year. In 2015, the number of people with dementia worldwide was around 46.8 million people (Smith et al., 2018). This number will double in 2030 to 65.7 million people and by 2050 people with dementia will more than triple to reach 115.4 million people. (Leocadie et al., 2020). Based on the report contained in the article on the prevalence of dementia, dementia sufferers in Indonesia are estimated to be around 1.2 million people and will increase to 2 million people in 2030 and 4 million people in 2050.

Cognitive function is generally caused by disorders of the central nervous system which include impaired oxygen supply to the brain, degeneration/aging, Alzheimer's disease and malnutrition (Ramli and Fadhillah, 2020). Dementia is one of the most common agerelated diseases and neurocognitive problems are one of the causes of psychological disorders in older people. Alzheimer's is one of the most common types of dementia in the elderly because of the proportion of people who range between $65 \%$ and $75 \%$ of dementia patients. Alzheimer's disease results in cognitive impairment in patients and memory loss and symptomatic symptoms that occur in the elderly with Alzheimer's. The main risk of Alzheimer's death is due to the death of brain cells, ignorance of the disease and its symptoms and knowledge of how to deal with it. (Bayahya et al., 2019). The problem of dementia has a profound impact on the lives of the elderly. The elderly suffering from dementia will experience various obstacles in terms of fulfilling daily life activities and social interactions with the surrounding community (Kerpershoek et al., 2018). People with dementia will also show symptoms of lack of memory and language, urinary and fecal incontinence, loss of balance and coordination and dependence on meeting daily needs. (Peixoto et al., 2018). People with dementia may have difficulty interacting with their physical and social environment. Symptoms of cognitive, behavioral, and psychological disorders can be treated with a variety of nonpharmacological interventions (Sobral and Pestana, 2020)
Virtual reality (VR) is a threedimensional environment created by a computer or simulated by a computer that synchronously stimulates the sensory system (sight, hearing) to create the illusion of reality that is very similar to the real world. (Appel et al., 2020). The advantages of using VR interventions include increasing accessibility and cost-effectiveness, creating immersive experiences, and providing immediate feedback based on individual performance. (Liao et al., 2019). Virtual reality is a technology that provides an artificially created interaction between the user and the environment. In recent years, with the advancement of technology, the use of VR has become more and more widespread. Beyond entertainment purposes, VR also finds purpose in specific fields of medicine such as rehabilitation and cognitive training (Chua et al., 2019). Virtual Reality is a tool for people living with dementia that aims to maintain sufferers who can live their lives independently provides a calming experience and is a tool for memory and cognitive stimulation. Virtual Reality is a highly intervening area for psychological interventions in general, and more specifically for the treatment of dementia and can improve the well-being of people with dementia (Sobral and Pestana, 2020).

Based on the description above, this is the basis of the reason for researchers to conduct literature studies to study tertiary data obtained from databases both with high reputations and from previous researchers in various countries discussing the effect of virtual reality on cognitive function in elderly people with dementia.

\section{METHODE}

This research was conducted using data obtained from 10 journals from several high and middle reputable databases. Before determining which journals to search, researchers looked for keywords that would help in searching for literature through Medical Subject Heading (MesH). The strategy used in finding articles is using the PICOS framework

The data used in this study were obtained from research conducted by previous researchers in the form of articles or journals contained in an international database consisting of Scopus, ProQuest, and Science Direct and published in 2015 to 2020. The research design was used in this scientific search. Namely randomized controlled trials, Quasy-Experiment, Qualitative Study and Case Study. 
The first step taken in the process of selecting journals is to search for journals in the database using keywords, then the researcher carries out a selection or filtering process on the abstract parts of the journals that are found and processed by filtering the text as a whole. In this section, the journals taken are journals that are following the objectives of the researcher and make boundaries such as the year of publication of the journal, language and search assistance operators such as the Boolean operator.

Based on the results of a literature search through the Scopus, ProQuest, and Science Direct databases, researchers found 758 journals that match the keywords used. The journals that were found were screened based on inclusion criteria, restrictions on the year of publication and language obtained 35 journals, then the existing journals were screened based on abstracts, types of articles, and types of research and 10 articles were used. Researchers used Mendeley as a literature review.

The Joanna Briggs Institute (JBI) Critical Appraisal is used to assess several types of Randomized Controlled Trial, Quasy Experimental, Qualitative Study, and Case Study using articles to analyze methodological quality in each study. A checklist based on The Joanna Briggs Institute (JBI) provided several questions to assess the quality of the study. The assessment criteria were given a score of 'yes', 'no', 'unclear', and no 'error'. In the calculation, each 'yes' score is assigned a point and the other is zero, then calculated and added up. A critical assessment to assess the eligibility of the studies was carried out by the researcher. If the research score is obtained $50 \%$ meets the critical criteria, the research is included in the inclusion criteria.

\section{RESULTS AND ANALYSISS}

This literature study research uses 10 international journals that have passed the screening period according to predetermined criteria based on the quality analysis of The JBI Critical Appraisal Tools. Of the 10 journals, the most widely used research designs to discuss the effect of virtual reality use on cognitive function in elderly people with dementia are randomized controlled trials (RCTs), quasiexperiments, qualitative studies, and case studies.

Respondents in this study were elderly people with both mild and severe cognitive impairments who came from various countries such as France, Canada, Thailand, Taiwan, Poland, Italy, and Korea. The sex of the respondents is the elderly male and female who are the oldest over 65 years. Based on the information contained in the literature, the elderly who are over 65 years of age are very susceptible to decreased cognitive function to the onset of dementia, therefore there is a need for appropriate interventions to maintain and improve cognitive function in the elderly.

One of the interventions that can be given is the use of virtual reality. In this VR intervention session, participants wore headmounted displays (HMD) and Sennheiser HD 221 headphones. The next stage was that participants watched an immersive virtual reality experience consisting of a series of natural films in the form of footage on the shores of rocky lakes, forests, icebergs, and sunny beaches. The series film was shown once for 20 minutes a day(Appel et al., 2020).

Virtual reality is one of the technologybased non-pharmacological interventions that can be used to help elderly patients with cognitive disorders. Research conducted by Manenti et al. (2020), showed that a significant increase in memory, language and visual construction abilities after the end of treatment using a face-to-face virtual reality-based cognitive rehabilitation system compared to the usual face-to-face cognitive treatment.

In a study conducted by Htut et al. (2018), participants were given virtual realitybased exercises using ten games from $\mathrm{X}$-box 360 (Flextronics, Wistron, Celestica, Foxconn). The game is carried out in 30 minutes and participants choose six games that involve upper and lower limb movements and balance exercises. The movements included in the game include Light Raise (stepping forward, backward, or sideways), Virtual Smash (the body moves the top and bottom), Stack'em up (moving the weight and the body ducks down a little to drop the box in the left space or right), One Ball Roll (using the left and right hands reciprocally to throw the ball so that it can drop the bottle, Super Saver (stepping aside to prevent the ball from hitting the goal), target kick (kicking the ball to hit the target, playing paddle panic ( Using one or both hands to catch and hit the ball), Body Bally (using your hands, feet, and head to hit the ball) and Bamp Bash (stepping forward, backward and moving sideways to avoid objects thrown by your opponent).

The results of this study indicate that virtual reality-based exercises can significantly increase the MoCA score of the elderly who are respondents in this study where the $p$-value is $<0.001$ or the $p$-value $<0.005$. This study also increased indicating that the participants' MoCA scores after being given balance training or balance training (Htut et al., 2018). This is in line 
with research conducted by Liao et al (2019). Where in this study, participants were given VR games for cognitive rehabilitation with program concepts inspired by IADL task simulations such as the mass rapid transit (MRT) ride. Participants who use the MRT in the context of VR are familiar with where the station gates, ticket vending machines and ATMs are located in the usual places and can see their current location with the station they are going to. The results of this study said that the group that had been given virtual reality-based cognitive rehabilitation showed a significant cognitive improvement, especially in the aspect of executive function.

Health sick continue to pay attention to the elderly who experience cognitive dysfunction. One of the actions given is to carry out cognitive rehabilitation using virtual reality. In a study conducted by Park, Jung, and Lee (2020), participants underwent cognitive rehabilitation using virtual reality in carrying out daily activities such as driving, bathing, cooking, and shopping. The results of this study indicate that the participants who followed the rehabilitation technique experienced an increase in cognitive function after using the Montreal Cognitive Assessment (MoCA) scale compared to the group who underwent conventional rehabilitation with simple game methods such as puzzles, card games, and others. The results of this study are in line with research conducted by White and Moussavi in 2016 which showed that respondents experienced an increase in the MoCA scale while undergoing treatment using a virtual reality environment navigation.

The elderly with dementia will show symptoms of memory impairment symptoms, warnings, orientation, and executive function as well as behavioral and psychological symptoms, one of which is apathy. In 2015, Manera et al Conducted research using an image-based rendered virtual reality system that is applied to elderly people with dementia who experience apathy and non-apathy. The results of this study indicate that apathetic elderly with dementia feel very satisfied and interested in the attention task and report a feeling of comfort and decreased experiencing and reporting. Apathetic participants were more interested in a virtual reality system of rehabilitation compared to other interventions.

In this study, participants were given simple word stimuli on a stereoscopic LED video wall. Participants sit in comfortable chairs, approximately 1.90 meters from the screen. Participants with the VR application use a wireless mouse that is placed on a small stool next to the chair so that the user's arm is in a resting position. The participant uses the mouse to move the target gray square character and clicks the mouse button to select the character. When the character is selected correctly, a green rectangular shape appears above the character, whereas if the selection is wrong a red rectangle will appear above the character. Before this activity, participants are given a practice scene to familiarize themselves with the assignment to be given (Manera et al., 2016).

Behavioral and psychological symptoms in dementia are common in elderly people with dementia and are very difficult to treat. Various interventions were carried out to manage this problem, one of which was by using virtual reality. Appel et al (2020), conducted a feasibility and pilot study using virtual reality to manage behavioral and psychological symptoms in dementia that occur in elderly with dementia who are undergoing hospitalization. The behavioral and psychological symptoms experienced by participants in this study included agitation, refusing medical treatment, exhibiting violent behavior towards staff and other patients, insomnia, irregular thoughts, and perceptual disturbances. The results of the study indicated that overall, participants felt relaxed and tolerated immersive VR so that this intervention could be recommended for all stages of dementia.

In rehabilitation programs related to cognitive impairment in the elderly with early stages of Alzheimer's dementia, various noninvasive approaches are used to help the elderly in daily cognitive activities. One of the approaches used is virtual reality. In research conducted by Bourrelier et al (2016), namely by providing rehabilitation techniques using virtual reality to train motor and postural skills for the elderly either with or without cognitive disruption. In this study, participants were given a scenario of harvesting fruit using a virtual environment and the results showed that the participants enjoyed the game and showed good perceptions of the elements that were set. Another study conducted by Zając - Lamparska et al (2019) also showed that virtual realitybased cognitive rehabilitation using the GRADY'S game for cognitive enhancement as well as a counterbalancing measure for cognitive decline experienced normally due to the aging process.

\section{DISCUSSION}

Over the past few years, interventions aimed at cognitive rehabilitation in older adults with decreased cognitive function have continued to be developed. As technological 
advances continue to develop, researchers in several countries are applying technologybased cognitive rehabilitation techniques to elderly people who experience cognitive decline by using virtual reality.

After exploring the ten articles reviewed, $70 \%$ of the articles explained that virtual reality can be used as cognitive rehabilitation in the elderly at both the mild, moderate, and severe stages. Cognitive rehabilitation using virtual reality can help improve cognitive function in older adults with cognitive impairment or dementia. This is in line with research conducted by (Park, Jung and Lee, 2020), where his research stated that participants who have been given virtual realitybased cognitive rehabilitation interventions to carry out various daily activities such as driving, bathing, cooking, and studying can stimulate several cognitive aspects such as attention, memory, problem problems, and executive training.

The rehabilitation program using virtual reality with a scenario of doing daily activities is an interesting and fun cognitive rehabilitation method that can increase the motivation of elderly participants to join the rehabilitation program. Increased interaction through motivation can aid thought processes by activating brain neurotransmitter pathways, such as the cholinergic and dopaminergic systems that help improve concentration and memory in the elderly. The equipment used in this study required continuous upper limb movement during rehabilitation activities. Physical exercise can affect cognitive functions such as executive function by increasing the levels of brain-derived neurotrophic factors and blood flow in the hippocampus resulting in beneficial metabolism for the body. In addition, physical exercise can stimulate the hypothalamic, pituitary, and adrenal axes which increase cortisol levels which increase thinking and memory skills. The results of this study indicate that the quality improvement in memory function is calculated by a cognitive assessment using the Montreal Cognitive Assessment (MoCA) scale, especially on the aspects of memory and attention(Park, Jung and Lee, 2020).

The Montreal Cognitive Assessment (MoCA) is based on the domain disorders that are often found in cognitive disorders, so this instrument is designed as a rapid screening instrument to assess these problems. The cognitive domains that use this instrument include concentration and concentration, executive functioning, memory, language, visuo constructive skills, conceptual thinking, computation, and orientation. The time used to assess cognitive function using the MoCA scale is about 10 minutes and the total score is 30 points and statistics if the score reaches 26 to 30 points (Girsang, 2018).

Research conducted by Manenti et al. (2020) said that cognitive rehabilitation techniques using virtual reality can improve several aspects of cognitive function such as memory, language, and visual construction abilities. In assessing cognitive function, there are several indicators which include orientation, language, attention, calculation, memory, construction, and reasoning (Polidori et. al., 2018 dalam Sunarti et al., 2019).

Regarding these aspects, virtual realitybased interventions also affect executive functions. This is evidenced by the results of research conducted by Liao et al (2019) which states that there is a significant increase in awareness, especially in the aspect of function after being given intervention using virtual reality. In this study, participants were given games for cognitive training using virtual reality with simulations of performing IADL tasks such as games on mass fast transportation (MRT). Participants use the MRT in the context of virtual reality and must know where the station gates, ticket vending machines, and ATMs are located in normal places. To complete this task, participants must see their current location and the station they are going to and need to collect the appropriate coins based on the chart to get a ticket.

Another IADL-based cognitive training scenario applied in the research conducted by Liao et.al (2019) is a game that is given a shop search and is given an indicator in the form of a large red cross when something is problematic. A participant must walk to the shop on the map in less than three minutes. If a participant fails to shop within two minutes, a red directional sign will appear to guide their way. Participants also provide a game scenario to become a kitchen chef, where participants in this scenario are in a fully equipped kitchen and the equipment is available to be used in preparing the dishes ordered.

IADL-based VR programs can effectively facilitate complex functions especially visual attention because participants practice these functional tasks repeatedly during rehabilitation. For example, the game of being a chef is specifically designed to practice planning and task shifting skills wherein the game, participants try to prepare food to order using available equipment and ingredients. Participants are said to show a good executive function if they can complete the game to perform these functional tasks well in the game of being a kitchen chef, participants can provide 
food according to orders and can use the ingredients and tools provided according to their function (Liao et al., 2019).

The executive function consists of a number of abilities which include the ability to initiate, plan, sequence, the ability to think abstractly, formulate strategies in problemsolving and the ability to move flexibly from one cognitive function to another. Many executive functions are supported by the frontal cortex and are associated with other parts of the brain that are closely related to the frontal cortex such as the temporal complex (Hoff \& Kremen, 2003 dalam Herdaetha, 2009).

Elderly with dementia, experiencing cognitive decline problems, generally will experience symptoms of BPSD (Behavioral and Psychological Symptoms of Dementia) and will find it difficult to improve. One of the nonpharmacological interventions used in BPSD organizations is virtual reality. Dementia sufferers who are exposed to nature, although it will be virtually beneficial in terms of reducing depression, stress, and reporting causes(Appel et al., 2020).

The use of virtual reality, apart from being an intervention for cognitive rehabilitation programs, can also be used for problems associated with Alzheimer's dementia that can be inhibited development by appropriate interventions. In research conducted by Howett et al (2020), showed that an entorhinal cortexbased virtual reality navigation task can differentiate between patients with mild cognitive impairment who are at low or high risk for dementia.

The aging process that occurs in the elderly will result in a decrease in various body functions, one of which is changes in cognitive function. Cognitive consists of several functions including orientation, language, attention, memory, judgment, problem problems, and executive abilities such as planning, evaluating, and evaluating (Poliodri et al., 2018 in Sunarti et al., 2019).

Decreased cognitive function is one of the main problems that occur in the elderly which is related to the degeneration process. The decline in cognitive function can affect the elderly in terms of patterns of interaction with family members, the environment in which they live and patterns of social activities so that they can result in a burden on the family, environment, and society (Sunarti et al., 2019). Decreased cognitive function, if not functioning early, can develop into dementia.

The problem of cognitive decline in the elderly can be overcome with various interventions, one of which is rehabilitation using technology-based interventions in the form of virtual reality. Virtual reality is a computer-generated technology that allows interaction between users and virtual environments (Liao et al., 2019). Virtual reality synchronously stimulates the sensory system which includes the senses of sight and hearing to create an illusion that is very similar to the real world (Appel et al., 2020). For people with dementia, virtual reality can be used as a tool to increase memory capacity and can stimulate cognition and can provide a calming experience for the elderly to be able to sustain their lives independently (Sobral and Pestana, 2020). The advantages of using virtual reality for elderly people with dementia are not only improving cognitive but also improving motor coordination, reducing behavioral and psychological behavior and can be used to treat cognitive disorders.

Rehabilitation programs related to cognitive and motor impairment in elderly people with dementia can use technologybased interventions. This action can provide sensations related to cognitive and motor tasks in everyday life through realistic stimuli. In research conducted by Bourrelier et al, (2016), participants gave a scenario of harvesting fruit that took place in a garden setting with the main tree in a virtual environment. About balance stimulation, the researcher provides a different space for action for two conditions, namely in the peripersonal space, wherein this space participants take action without legs and extrapersonal space that requires movement in its implementation. In this study, it is said that this important point in rehabilitation can stimulate sensorimotor and cortical plasticity.

The degeneration process that occurs in elderly pandas occurs in various body systems, one of which is the nervous system. On the nerves, the first area to undergo a degeneration process is the entorhinal cortex, which is a typical early stage in Alzheimer's dementia. Changes that occur associated with Alzheimer's dementia can be detected in the function of the cortex so that it can support the early development of Alzheimer's. Virtual reality is one of the interventions that can be used to check for these abnormalities. In research conducted by Howett et al (2020), said that the task of virtual reality navigation based on the entorhinal cortex can distinguish patients with mild cognitive impairment who are at low or high risk for dementia.

Based on the description above, it can be said that the elderly who have decreased cognitive function can be handled by carrying out cognitive rehabilitation using technologybased interventions, namely virtual reality. Besides being used for rehabilitation, virtual 
reality can also be used to manage behavioral and psychological symptoms, improve motor coordination and detect cognitive decline that has the potential to continue in the dementia stage. Dementia problems that occur in the elderly cannot be cured so that various systems of rehabilitation to maintain cognitive function are needed. Virtual reality is an alternative rehabilitation system that can be used to treat cognitive decline in the elderly.

\section{CONLUSION}

The aging process that occurs in the elderly can cause problems with various wrong body functions, namely cognitive dysfunction. The decline in cognitive function that occurs in the elderly, if not supported early, can develop into dementia. In cognitive rehabilitation, one technology-based intervention that can be used in virtual reality.

The advantages of using virtual reality for elderly people with dementia are not only improving cognitive but also improving motor coordination, reducing behavioral and psychological behavior, and can be used to treat cognitive disorders.

\section{CONLICT OF INTEREST}

The writing of this literature review was carried out independently so that there were no conflicts of interest in its administration.

\section{REFERENCES}

Appel, L., Kisonas, E., Appel, E., Klein, J., Bartlett, D., Rosenberg, J., Smith, C. (2020) 'Introducing virtual reality therapy for inpatients with dementia admitted to an acute care hospital: learnings from a pilot to pave the way to a randomized controlled trial', Pilot and Feasibility Studies. Pilot and Feasibility Studies, 6(1), pp. 1-16. doi: 10.1186/s40814-020-00708-9.

Bayahya, A. Y., Alhalabi, W., Al-Amri, Sultan H., Albeshri, Aiiad A., El-Missiry, Ahmed A. (2019) 'Computer Generated Environment Utilizing Machine Learning Algorithms to Evaluate Dementia Patients', Procedia Computer Science. Elsevier B.V., 163, pp. 275-282. doi: 10.1016/j.procs.2019.12.109.

Bourrelier, J., Ryard, J., Dion, M., Merienne, F., Manckoundia, P., Mourey, F. (2016) 'Use of a Virtual Environment to Engage Motor and Postural Abilities in Elderly Subjects With and Without Mild Cognitive Impairment (MAAMI Project)', Irbm. Elsevier Masson SAS,
37(2), pp. 75-80. doi: 10.1016/j.irbm.2016.02.007.

Chua, S. I. L., Tan, Ngiap C., Wong, W. T., Allen, J. C., Quah, J. H. M., Malhotra, R., Østbye, T. (2019) 'Virtual reality for screening of cognitive function in older persons: Comparative study', Journal of Medical Internet Research, 21(8). doi: 10.2196/14821.

Coelho, T., Marques, C., Moreira, D., Soares, M., Portugal, P., Marques, A., Ferreira, A. R., Martins, S., Fernandes, L. (2020) 'Promoting reminiscences with virtual reality headsets: A pilot study with people with dementia', International Journal of Environmental Research and Public Health, 17(24), pp. 1-13. doi: 10.3390/ijerph17249301.

Girsang, G. (2018) Perbedaan Skor Montreal Cognitive Assessment Versi Indonesia (Moca-Ina) Antara Laki-Laki Dengan Skizofrenia Yang Mendapat Risperidon Dengan Penambahan Omega-3, Dan Yang Hanya Mendapat Risperidon Di Rumah Sakit Jiwa Prof. Dr. Muhammad Ildrem Medan. http://repositori.usu.ac.id/bitstream/han dle/123456789/3831/107106005.pdf?s equence $=1$ \&isAllowed $=y$

Herdaetha, A. (2009) Keefektifan Terapi Remediasi Dengan Bantuan Komputer Terhadap Disfungsi Kognitif Pasien Skizofrenia Kronis Di Panti Rehabilitasi Budi Makarti Boyolali.

Howett, D., Castegnaro, A, Krzywicka, K., Hagman, J., Marchment, D., Henson, R., Rio, M., King, John A., Burgess, N., Chan, D. (2019) 'Differentiation of mild cognitive impairment using an entorhinal cortex-based test of virtual reality navigation', Brain, 142(6), pp. 1751-1766. doi: 10.1093/brain/awz116.

Htut, T. Z. C., Hiengkaew, V., Jalayondeja, C., Vongsirinavarat, M. (2018) 'Effects of physical, virtual reality-based, and brain exercise on physical, cognition, and preference in older persons: a randomized controlled trial', European Review of Aging and Physical Activity. European Review of Aging and Physical Activity, 15(1), pp. 1-13. doi: 10.1186/s11556-018-0199-5.

Kerpershoek, L., de Vugt, M., Wolfs, C., Woods, B., Jelley, H., Orrell, M., Stephan, A., Bieber, A., Meyer, G., Selbaek, G., Handels, R., Wimo, A., Hopper, L., Irving, K., Marques, M., Gonçalves-Pereira, M., Portolani, E., Zanetti, O., Verhey, F. (2018) 'Needs 
and quality of life of people with middlestage dementia and their family carers from the European Actifcare study. When informal care alone may not suffice', Aging and Mental Health. Taylor \& Francis, 22(7), pp. 897-902. doi: 10.1080/13607863.2017.1390732.

Lau, Y. W., Vaingankar, J. A., Abdin, E., Shafie, S., Jeyagurunathan, A., Zhang, Y., Magadi, H., Ng, Li L.,Chong, S. A., Subramaniam, M. (2019) 'Social support network typologies and their association with dementia and depression among older adults in Singapore: A cross-sectional analysis', BMJ Open, 9(5), pp. 1-10. doi: 10.1136/bmjopen-2018-025303.

Leocadie, M. C., Morvillers, J. M., Pautex, S., Rothan-Tondeur, M. (2020) 'Characteristics of the skills of caregivers of people with dementia: Observational study', BMC Family Practice. BMC Family Practice, 21(1), pp. 1-13. doi: 10.1186/s12875-02001218-6.

Liao, Y. Y., Hsuan Chen, I., Lin, Yi J., Chen, Y., Hsu, W. C. (2019) 'Effects of virtual reality-based physical and cognitive training on executive function and dualtask gait performance in older adults with mild cognitive impairment: A randomized control trial', Frontiers in Aging Neuroscience, 10(JUL). doi: 10.3389/fnagi.2019.00162.

Manenti, R., Gobbi, E., Baglio, F., Macis, A., Ferrari, C., Pagnoni, I., Rossetto, F., Tella, S. D., Alemanno, F., Cimino, V., Binetti, G., lannaccone, S., Bramanti, P. (2020) 'Effectiveness of an Innovative Cognitive Treatment and Telerehabilitation on Subjects With Mild Cognitive Impairment: A Multicenter, Randomized, Active-Controlled Study', 12(November). doi: 10.3389/fnagi.2020.585988.

Manera, V., Chapoulie, E., Bourgeois, J., Guerchouche, R., David, R., Ondrej, J., Drettakis, G., Robert, P. (2016) 'A feasibility study with image-based rendered virtual reality in patients with mild cognitive impairment and dementia', PLoS ONE, 11(3), pp. 1-15. doi: 10.1371/journal.pone.0151487.

Nankinga, P. N., Maling, S., Chemali, Z., Wakida, E. K., Obua, C., Okello, E. S. (2020) 'Informal support for people with Alzheimer's disease and related dementias in rural Uganda: A qualitative study', International Journal of Mental Health Systems. BioMed
Central, 14(1), pp. 1-11. doi: 10.1186/s13033-020-00364-9.

Park, J.-S., Jung, Y.-J. and Lee, G. (2020) 'Virtual Reality-Based Cognitive-Motor Rehabilitation in Older Adults with Mild Cognitive Impairment: A Randomized Controlled Study on Motivation and Cognitive Function', Healthcare, 8(3), p. $335 . \quad$ doi: 10.3390/healthcare8030335.

Peixoto, R. I., Silveira, V. M., Zimmermann, R. D., de M. Gomes, A. (2018) 'End-of-life care of elderly patients with dementia: A cross-sectional study of family carer decision-making', Archives of Gerontology and Geriatrics. Elsevier, 75(September 2017), pp. 83-90. doi: 10.1016/j.archger.2017.11.011.

Ramli, R. and Fadhillah, M. N. (2020) 'Faktor yang Mempengaruhi Fungsi Kognitif pada Lansia', Window of Nursing Journal, 01(01), pp. 22-30. doi: 10.33096/won.v1i1.21.

Smith, R., Drennan, V., Mackenzie, A., Greenwood, N. (2018) 'The impact of befriending and peer support on family carers of people living with dementia: $A$ mixed methods study', Archives of Gerontology and Geriatrics. Elsevier, 76(March), pp. 188-195. doi: 10.1016/j.archger.2018.03.005.

Sobral, M. and Pestana, M. H. (2020) 'Virtual reality and dementia: $A$ bibliometric analysis', European Journal of Psychiatry. Asociaci\&oacute;n Universitaria de Zaragoza para el Progreso de la Psiquiatr\&iacute;a y la Salud Mental, 34(3), pp. 120-131. doi: 10.1016/j.ejpsy.2020.04.004.

Sunarti, S., Ratnawati, R., Nugrahenny, D., Mattalitti, G. N. M., Rahmad, R., 'Budianto, R., Pratiwi, I. C., Prakosa, A. G. (2019) Prinsip Dasar Kesehatan Lanjut Usia. 1st edn. Malang: UB Press.

White, P. J. F. and Moussavi, Z. (2016) 'Neurocognitive treatment for a patient with Alzheimer's disease using a virtual reality navigational environment', Journal of Experimental Neuroscience, 2016(10), pp. 129-135. doi: 10.4137/JEn.s40827.

Wibowo, H., Putri, T. W., Mutiyarsih, Roeslie, E. (2015) 'Strategi Nasional Penanggulanan Penyakit Alzheimer Dan Demensia Lainnya: Menuju Lanjut Usia Sehat Dan Produktif', Kementerian Kesehatan Republik Indonesia, p. 21. 
Zając-Lamparska, L., Wiłkość-Dębczyńska, M., Wojciechowski, A., Podhorecka, M., Polak-Szabela, A., Warchoł, Ł., Kędziora-Kornatowska, K.,

Araszkiewicz, A., Izdebski, P. (2019) 'Effects of virtual reality-based cognitive training in older adults living without and with mild dementia: A pretest-posttest design pilot study', BMC Research Notes. BioMed Central, 12(1), pp. 1-8. doi: 10.1186/s13104019-4810-2. 